\title{
Erratum to: Extension of a Decision Procedure for a Fragment of Hybrid Logic with Binders
}

\author{
Marta Cialdea Mayer
}

Published online: 21 May 2015

(C) Springer Science+Business Media Dordrecht 2014

\section{Erratum to: J Autom Reasoning \\ DOI 10.1007/s10817-014-9307-z}

Due to an oversight in production, the article title was incorrectly modified. The correct article title is shown above. The publisher sincerely apologizes for this mistake.

The online version of the original article can be found at http://dx.doi.org/10.1007/s10817-014-9307-z.

M. Cialdea Mayer $(\bowtie)$

Università di Roma Tre, Roma, Italy

e-mail: cialdea@dia.uniroma3.it 